OPEN ACCESS

Edited by:

Peter Flatt,

Ulster University, United Kingdom

Reviewed by:

Nigel Irwin,

Ulster University, United Kingdom

Linda Ahlkvist,

Skåne University Hospital, Sweden

Susanne Ullrich,

Helmholtz-Gemeinschaft Deutscher

Forschungszentren (HZ), Germany

${ }^{*}$ Correspondence:

Wei He

wei.he@tu-bs.de

Kathrin Maedler

kmaedler@uni-bremen.de

Specialty section: This article was submitted to

Gut Endocrinology,

a section of the journal

Frontiers in Endocrinology

Received: 18 April 2021

Accepted: 18 June 2021

Published: 05 July 2021

Citation:

HeW, Rebello OD, Henne A, Nikolka F, Klein T and Maedler K (2021) GLP-2 Is

Locally Produced From Human Islets and Balances Inflammation Through an Inter-Islet-Immune Cell Crosstalk.

Front. Endocrinol. 12:697120.

doi: 10.3389/fendo.2021.697120

\section{GLP-2 Is Locally Produced From Human Islets and Balances Inflammation Through an Inter-Islet-Immune Cell Crosstalk}

\author{
Wei He ${ }^{1,2 *}$, Osmond D. Rebello ${ }^{1}$, Antonia Henne ${ }^{2,3}$, Fabian Nikolka ${ }^{2}$, Thomas Klein ${ }^{4}$ \\ and Kathrin Maedler ${ }^{1 *}$
}

${ }_{1}^{1}$ Centre for Biomolecular Interactions Bremen, University of Bremen, Bremen, Germany, ${ }^{2}$ Department of Bioinformatics and Biochemistry and Braunschweig Integrated Center of Systems Biology (BRICS), Technische Universität Braunschweig, Braunschweig, Germany, ${ }^{3}$ Faculty of Chemistry and Pharmacy, Julius-Maximilians-Universität Würzburg, Würzburg, Germany, ${ }^{4}$ CardioMetabolic Diseases Research, Boehringer Ingelheim GmbH \& Co. KG, Biberach, Germany

Glucagon-like peptide-1 (GLP-1) shows robust protective effects on $\beta$-cell survival and function and GLP-1 based therapies are successfully applied for type-2 diabetes (T2D) and obesity. Another cleavage product of pro-glucagon, Glucagon-like peptide-2 (GLP-2; both GLP-1 and GLP-2 are inactivated by DPP-4) has received little attention in its action inside pancreatic islets. In this study, we investigated GLP-2 production, GLP-2 receptor (GLP-2R) expression and the effect of GLP-2R activation in human islets. Isolated human islets from non-diabetic donors were exposed to diabetogenic conditions: high glucose, palmitate, cytokine mix (IL-1 $\beta /$ IFN- $\gamma$ ) or Lipopolysaccharide (LPS) in the presence or absence of the DPP4-inhibitor linagliptin, the TLR4 inhibitorTAK-242, the GLP-2Ragonist teduglutide and/or its antagonist GLP-2(3-33). Human islets under control conditions secreted active GLP-2 (fulllength, non-cleaved by DPP4) into the culture media, which was increased by combined high glucose/palmitate, the cytokine mix and LPS and highly potentiated by linagliptin. Low but reproducible GLP-2R mRNA expression was found in all analyzed human islet isolations from 10 donors, which was reduced by pro-inflammatory stimuli: the cytokine mix and LPS. GLP2R activation by teduglutide neither affected acute or glucose stimulated insulin secretion nor insulin content. Also, teduglutide had no effect on high glucose/palmitate- or LPS-induced dysfunction in cultured human islets but dampened LPS-induced macrophage-dependent IL1B and IL10 expression, while its antagonist GLP-2(3-33) abolished such reduction. In contrast, the expression of islet macrophage-independent cytokines IL6, IL8 and TNF was not affected by teduglutide. Medium conditioned by teduglutide-exposed human islets attenuated M1-like polarization of human monocyte-derived macrophages, evidenced by a lower mRNA expression of pro-inflammatory cytokines, compared to vehicle treated islets, and a reduced production of itaconate and succinate, marker metabolites of proinflammatory macrophages. Our results reveal intra-islet production of GLP-2 and GLP-2R expression in human islets. Despite no impact on $\beta$-cell function, local GLP-2R activation reduced islet inflammation which might be mediated by a crosstalk between endocrine cells and macrophages.

Keywords: GLP-2, islets, beta-cell, inflammation, diabetes, GLP-2R, alpha-cell 


\section{INTRODUCTION}

Proglucagon-derived peptides (PGDPs) are structurally related gut hormones produced from alternative post-translational enzymatic processing of proglucagon, one of them is glucagon produced from $\alpha$-cells of pancreatic islets, two other ones are the sister peptides glucagon-like peptides 1 and 2 (GLP-1 and -2), all encoded in the proglucagon gene (GCG) (1). Stimulated by the ingestion of nutrients, GLP-1 and GLP-2 are co-secreted from the enteroendocrine $\mathrm{L}$ cells of the intestine through proglucagon processing by prohormone convertase 1/3 (PC1/3) (1).

Classically, in pancreatic islets, the proglucagon gene is highly expressed in $\alpha$-cells; it is cleaved by PC2 to produce glucagon in response to lowering blood glucose levels. More recent studies have also revealed pancreatic $\alpha$-cells' production of GLP-1 (2-5). In line with this, $\mathrm{PC} 1 / 3$ is expressed in murine and human $\alpha$ cells (2-6). Due to the nature of co-production of GLP-1 and GLP- 2 by PC1/3, it is assumable that GLP-2 may also be locally produced in pancreatic islets.

GLP-1 and GLP-2 exert multiple direct and indirect actions on nutrient processing and energy metabolism (1), whereas they are rapidly degraded by dipeptidyl peptidase-4 (DPP4), an ubiquitously expressed proteolytic enzyme, which cleaves both GLP-1 and GLP-2 into inactive forms (7). Due to GLP-1's robust potentiation of glucose stimulated insulin secretion, inhibition of glucagon secretion, gastric emptying and promotion of satiety, various DPP4-inhibitors as well as agonists of the glucagon-like peptide-1 receptor (GLP-1R) are established in the therapy of type 2 diabetes (T2D) (8). The GLP-2R agonist teduglutide is approved for treating short bowel syndrome, as GLP-2 promotes intestine growth and nutrient absorption (9). While the beneficial role of intra-islet GLP-1 action has been extensively investigated, the knowledge of local GLP-2 action in islets is very limited.

There is some controversy of the expression of both GLP-1R and GLP-2R, mainly because of the lack of sufficiently sensitive antibodies. While GLP-1R is widely expressed among organs, GLP-2R expression is restricted and was only found and confirmed primarily in enteroendocrine cells and enteric neurons of the GI tract, subepithelial myofibroblasts and in some regions of the central nervous system (CNS) subepithelial myofibroblasts and in some regions of the CNS $(9,10)$. Lesser GLP-2R protein was found in human and rodent islets and localized to the $\alpha$-cell with proglucagon colocalization (11). In line with this, GLP-2 acutely stimulates glucagon secretion (11). Consistent but low GLP-2R mRNA was confirmed in rodent $\alpha$ cell lines as well as in a human $\beta$-cell line and in mouse islets (12), the latter being in contrast to a more recent study (13). GLP-2 had no effect on glucose-stimulated insulin secretion (GSIS) in isolated mouse islets (12).

As there is limited knowledge on the impact of GLP-2R activation in human islets, this study was initiated to investigate intra-islet production of GLP-2 and effects of GLP-2R activation in isolated human islets, with a focus on $\beta$-cell function and islet inflammation. Studies revealed robust secretion of GLP-2 from human islets with enhanced GLP-2 production by diabetogenic and proinflammatory conditions. However, GLP-2 agonism by the DPP4-resistant agonist teduglutide had no effect on insulin secretion in cultured human islets, whereas it dampened LPSinduced expression of IL-1 $\beta$ and IL-10. Further experiments with islet conditioned medium suggested a GLP-2 mediated protection from a pro-inflammatory crosstalk between endocrine cells and islet macrophages.

\section{METHODS}

\section{Human Islet Isolation, Culture, Treatment, and GLP-2 Analysis}

Human islets were isolated from pancreases of non-diabetic organ donors (both males and females) at the Universities of Wisconsin, Lille or ProdoLabs and cultured on Biocoat Collagen I coated dishes (\#356400, Corning, ME, USA referred to as extracellular matrix (ECM)). Human islets were cultured in complete CMRL-1066 (Invitrogen) medium at $5.5 \mathrm{mM}$ glucose and exposed to complex diabetogenic conditions: $22.2 \mathrm{mM}$ glucose, $0.5 \mathrm{mM}$ palmitic acid, the mixture of $2 \mathrm{ng} / \mathrm{ml}$ recombinant human IL-1 $\beta$ (R\&D Systems, Minneapolis, MN) plus $1,000 \mathrm{U} / \mathrm{ml}$ recombinant human IFN- $\gamma$ (Pepro Tech, Rocky Hill, New Jersey) for $72 \mathrm{~h}$. To induce maximal TLR4 activation, attached islets were serum-starved for $6 \mathrm{~h} \mathrm{(14)}$ and then treated with the TLR4 ligand lipopolysaccharide (LPS, $20 \mu \mathrm{g} / \mathrm{ml}$, from $E$. coli O111:B4, Sigma-Aldrich, Steinheim, Germany) for 24h with or without $10 \mu \mathrm{M}$ TLR4 inhibitor TAK-242 [patent by Takeda Pharmaceutical (Osaka, Japan), synthesized by Servier (Suresnes, France) according to the published chemical structure $(15,16)]$. Palmitic acid was dissolved as described previously (17). The DPP4-inhibitor linagliptin (30 nM), or the DPP4-resistant GLP2 analogue and GLP-2R agonist teduglutide $(10 \mathrm{nM})$ with and without the GLP-2R antagonist GLP-2(3-33) (5 nM, all Biotrend, Cologne, Germany) were added to the respective treatment conditions. Cell culture supernatants were immediately snapfrozen and later analyzed by an inhouse established assay to specifically recognize active GLP-2 as described before (18). All human islet experiments were performed in the islet biology laboratory, University of Bremen, conducted in strict accordance with the World Medical Association's Declaration of Helsinki as well as with all relevant institutional and national guidelines, with the appropriate institutional ethics committee's prior approval. The studies involving material from human organ donors were reviewed and approved by the Ethics Committee of the University of Bremen. The study complied with all relevant ethical regulations for work with human cells for research purposes. Organ donors are not identifiable and anonymous, such approved experiments using human islet cells for research is covered by the NIH Exemption 4 (Regulation PHS 398). Human islets were distributed by the two JDRF and NIH supported approved coordination programs in Europe (Islet for Basic Research program; European Consortium for Islet Transplantation ECIT) and in the US (Integrated Islet Distribution Program IIDP) (19).

\section{Assay for Active GLP-2}

For detection of active GLP-2, a Luminex based assay compatible with the Luminex platform was developed by NMI, University of 
Tübingen, Germany, in collaboration with Boehringer Ingelheim GmbH \& Co. KG, Biberach/Riss, Germany. The Peptide sequence (HADGSFSD) in the $\mathrm{N}$-terminus was synthesized as Cys-Doa-Doa (8-amino-3,6-dioxaoctanoic acid) to increase accessibility of the immunogenic peptide containing variants of the primary sequence of interest. Cystein was included to allow immobilization via maleimide groups on the activated carrier proteins (BSA and Ovalbumin). Monoclonal and polyclonal antibodies to the above sequence were generated in rats and rabbits, respectively. Cross reactivity to GLP-1 was analyzed using the multiplex Luminex assay platform on a Luminex 100 system in accordance to classical Luminex based assays. Briefly, $20 \mu \mathrm{l}$ of sample were incubated in $100 \mu \mathrm{l}$ ELISA blocking buffer (\#1112589, Roche Diagnostics GmbH, Mannheim, Germany) in the presence of $20 \mu \mathrm{l}$ suspension of microparticles (1000 beads linked to Mab to active GLP-2) and incubated overnight at $10^{\circ} \mathrm{C}$. After washing 3 times with $100 \mu \mathrm{l} 0.05 \%$ Tween 20 in PBS, $40 \mu \mathrm{l}$ biotinylated detection polyclonal antibody solution (active GLP-2, stock solution $0.1 \mathrm{mg} / \mathrm{ml}$; diluted 1:50 in ELISA blocking buffer) was added and incubated on a shaker for $2 \mathrm{~h}$ in the dark $\left(22^{\circ} \mathrm{C}\right)$. After washing, $40 \mu \mathrm{l}$ of streptavidin-PE $(2 \mu \mathrm{g} / \mathrm{ml}$ diluted 1:500 in ELISA blocking buffer) was added and incubated on a shaker for $30 \mathrm{~min}$. in the dark $\left(22^{\circ} \mathrm{C}\right)$. After washing, plate was run on a Luminex 100. Detection limit of active GLP-2 was $20 \mathrm{pg} / \mathrm{ml}$ with minimal cross reactivity to GLP-1.

\section{RNA Extraction and Quantitative RT-PCR Analysis}

Total RNA was isolated from cultured human islets with a Trizol extraction system (TriFast, PEQLAB GmbH, Erlangen, Germany), cDNA synthesis and quantitative RT-PCR was performed as previously described (14). The following TaqMan ${ }^{\circledR}$ Gene Expression Assays (Applied Biosystems, Forster City, CA) were used: IL1B (Hs01555413_m1), IL6 (Hs99999032_m1), TNF (Hs99999043_m1), IL8 (Hs00174103_m1), IL10 (Hs00961622_ m1), PPIA (Hs99999904_m1).

\section{Insulin Secretion}

Glucose-stimulated insulin secretion (GSIS) was performed as described previously (14). Briefly, human islets were preincubated in Krebs-Ringer bicarbonate buffer (KRB) containing $2.8 \mathrm{mM}$ glucose for $30 \mathrm{~min}$, followed by KRB buffer containing 2.8 $\mathrm{mM}$ glucose for $1 \mathrm{~h}$ ("basal secretion") and then an additional $1 \mathrm{~h}$ in KRB containing $16.7 \mathrm{mM}$ glucose ("stimulated secretion") with or without the long-acting agonist of the GLP-1 receptor (GLP-1R) exendin-4 (10 nM; Sigma), or teduglutide (10 nM). Islets were washed with PBS and lysed with RIPA lysis buffer to extract total protein, followed by BCA measurement of protein concentration. Secreted insulin and insulin content from total protein were determined with human insulin ELISA kit (ALPCO Diagnostics, Salem, NH), and normalized to total protein concentration.

\section{M1 Polarization of Human MDMs in Islet-Conditioned Medium}

Primary monocytes isolated from human buffy coats using Biocoll $^{\circledR}$ (Bio\&SELL, Feucht, Germany) and CD14 microbeads
(Miltenyi, Bergisch Gladbach, Germany) were seeded onto tissue culture dishes $(1 \times 10$ e6 cells/ml) in RPMI 1640 medium containing $50 \mathrm{U} / \mathrm{ml}$ macrophage colony-stimulating factor (MCSF; ImmunoTool, Friesoythe, Germany) for 6 days to induce macrophage differentiation. Medium of cultured human islets treated with teduglutide alone or combined with GLP-2(3-33) for $24 \mathrm{~h}$ was collected from 3 different islet isolations and these media were pooled and designated as islet-conditioned medium.

Differentiated macrophages were then pre-cultured in isletconditioned medium 1:4 diluted by standard RPMI 1640 medium for $2 \mathrm{~h}$, followed by addition of $200 \mathrm{ng} / \mathrm{ml}$ LPS and $1,000 \mathrm{U} / \mathrm{ml} \mathrm{IFN}-\gamma$ for 8 hours to induce M1-like polarization.

\section{Extraction of Intracellular Metabolites and Total RNA From MDMs}

Extraction was performed as previously described (20). Briefly, MDMs on 12-well plates were washed with $0.9 \% \mathrm{NaCl}$ and quenched with $0.25 \mathrm{ml}$ of $-20^{\circ} \mathrm{C}$ methanol. After adding an equal volume of $4^{\circ} \mathrm{C}$ deionized water containing $1 \mu \mathrm{g} / \mathrm{ml} \mathrm{D}_{6^{-}}$ pentanedioic acid (C/D/N Isotopes, Quebec, Canada) as internal standard, cells were disrupted and collected with cell scrapers and transferred to tubes pre-added with $0.25 \mathrm{ml}-20^{\circ} \mathrm{C}$ chloroform. The extracts were vortexed at $1400 \mathrm{rpm}$ for $20 \mathrm{~min}$ at $4^{\circ} \mathrm{C}$ and centrifuged at $17,000 \mathrm{~g}$ for $5 \mathrm{~min}$ at $4^{\circ} \mathrm{C} .0 .3 \mathrm{ml}$ of the upper aqueous phase was transferred into gas chromatography compatible glass vials and then dried under vacuum at $4^{\circ} \mathrm{C}$ in CentriVap Concentration System (Labconco, Kansas City, Missouri). The interphase of the cell extracts was collected for total RNA isolation using NucleoSpin ${ }^{\circledR}$ RNA isolation kit (Macherey-Nagel, Düren, Germany).

\section{GC-MS Measurement of Intracellular Metabolites of MDMs}

GC-MS measurement was performed as described (20), using an Agilent 7890B gas chromatograph equipped with a $30 \mathrm{~m} \mathrm{DB}$ $35 \mathrm{~ms}$ and $5 \mathrm{~m}$ Duraguard capillary column (Agilent, Santa Clara, California) for separation of derivatized metabolites, and an Agilent 5977B MSD system (Agilent) for measurement of metabolites, followed with data processing using the Metabolite Detector software (21).

\section{Immunofluorescence}

Isolated human islets cultured on ECM dishes were fixed in Bouin's solution for $15 \mathrm{~min}$ before embedding in paraffin as previously described (14). 4- $\mu \mathrm{m}$ sections were deparaffinized, rehydrated and incubated overnight at $4^{\circ} \mathrm{C}$ with primary antibodies against hGLP2R (1:100; LS-A1312), hGLP-2R (1:100, C36446, both Lifespan Biosciences, Seattle, WA), guinea pig anti-insulin (\#A0546, 1:100, Dako, Glostrup, Denmark) or mouse anti-glucagon (\#G2654, 1:100, Sigma-Aldrich, Steinheim, Germany), followed by incubation with FITC or Cy3-conjugated secondary antibody (Jackson Immuno Research Laboratories, West Grove, PA) at room temperature for 1h. Slides were mounted with Vectashield with DAPI (Vector Labs, Burlingame, Ca). Fluorescence was analyzed using a Nikon MEA53200 microscope (Nikon GmbH, Dusseldorf, Germany) and images were acquired using NIS-Elements software (Nikon). 


\section{Statistical Analysis}

All values were expressed as means \pm SEM with the number of independent individual experiments (biological replicates) presented in the figure legends. The different groups were compared by paired two-tail Students t-test (for two groups) or one-way ANOVA with Dunnet's post-test (for multiple groups) or two-way ANOVA with Sidak's post-test (for two conditions) as stated in the figure legends. $\mathrm{P}$ value $<0.05$ was considered statistically significant.

\section{RESULTS}

\section{GLP-2 Secretion From Isolated Human Islets}

Since GLP-1 and GLP-2 are theoretically co-produced during enzymatic cleavage of proglucagon by $\mathrm{PC} 1 / 3$, one can assume that besides GLP-1, also GLP-2 is locally produced in pancreatic islets. To prove this hypothesis, we cultured human islets isolated from non-diabetic donors for $72 \mathrm{~h}$, followed by the analysis of the active form of GLP-2 in the culture medium. The mean concentration of secreted active GLP-2 from four human islet isolations was $1.5 \pm 0.3 \mathrm{ng} / 100$ islets (Figure 1A). A combined high glucose/palmitate exposure and the mixed proinflammatory cytokines IL- $1 \beta /$ IFN- $\gamma$ increased GLP-2 secretion 2.9- and 1.8-fold, while high glucose or palmitate alone had no significant effect (Figure 1A). As expected, linagliptin, a DPP4inhibitor clinically used for treating T2D, highly increased the amount of active GLP-2 in all conditions (Figure 1B), in line with its activity to block cleavage of GLP-2 by DPP4, similar to its effect on GLP-1 secretion from human islets (6). A direct comparison of GLP-1 and GLP-2 from the same islet isolations of our earlier study (6) revealed a similar range of secreted active GLP-1 and active GLP-2 from human islets (Figure 1C). We next treated isolated human islets with LPS for $24 \mathrm{~h}$, a condition we used previously to induce islet inflammation (22). LPS induced a 2.2-fold increase in active GLP-2 secretion (Figure 1D). The TLR4 inhibitor TAK-242 completely abolished such increase, confirming the TLR4-dependent effect of LPS (Figure 1E). Our results hereby verify intra-islet production of GLP-2, which is significantly increased by both high glucose/palmitate and by TLR 4 activation.

\section{GLP-2R Expression in Isolated Human Islets}

While there is previous controversy on GLP-2R expression in mouse islets (11-13), little is known in human islets. Therefore, we tested GLP2R mRNA levels in isolated human islets from 10 non-diabetic donors. All samples exhibited low but reliable expression of GLP2R (Ct 30-35), and the expression levels relative to housekeeping gene PPIA ranged from 0.00009 to 0.00226 (Figure 2A). Gluco- and lipotoxic treatment conditions (high glucose, palmitate or their combination) had no significant impact on GLP2R expression, while highly pro-inflammatory conditions, such as the cytokine mix of IL- $1 \beta /$ IFN- $\gamma$ (Figure 2B) and TLR4 activation by LPS (Figure 2C) remarkably reduced GLP2R mRNA levels. Linagliptin, which increased active GLP-2, had no significant effect on GLP2R expression (Figure 2B).

A previous study manifests $\alpha$-cell localization of GLP-2R in human islets by immunohistochemistry with a non-commercial antibody (11). In contrast, previous elegant scRNA sequencing analyses, could not identify GLP-2R in any of the islet cell types (23, 24). The scRNA sequencing database of human islets (http://hiview. case.edu/public/BetaCellHub/Primaryislet.php) $(25,26)$ localized expression of GLP2R mRNA exclusively in pancreatic stellate cells. Using a previously evaluated commercial antibody to human GLP-2, whose specificity against hGLP-2R has been examined by blocking with its GLP-2R control peptide $(27,28)$ as well as a second mouse monoclonal antibody to human GLP-2R delivered some GLP-2R co-staining with insulin of very little intensity in isolated human islets from numerous islet isolations (not shown). Because of the low mRNA expression values together with the absent GLP-2R expression from previous RNA-Seq databases, we assume a potential insufficient specificity of these antibodies used by us and others before. While we found GLP2R mRNA is reliably but lowly expressed in human islets, future in-depth studies are required to clarify its cellular localization in the human pancreas using highly sensitive and specific analyses.

\section{Intra-Islet GLR-2R Activation With No Impact on $\beta$-Cell Function}

Considering the intra-islet GLP-2 secretion and low GLP2R expression, we then investigated a possible local action of GLP-2 in human islets on insulin secretion by applying the DPP4-resistant GLP-2R agonist teduglutide (9) with and without the GLP-2R antagonist GLP-2(3-33), which has been shown to antagonize GLP-2R signaling in various cellular and animal models (29), but when applied alone also acts as partial GLP$2 \mathrm{R}$ agonist $(29,30)$. Concentrations were based on previous published studies in GLP-2R expressing cells, rodent and human $\beta$-cell lines and human islets, respectively $(6,12,30,31)$.

Chronic exposure of human islets to classical diabetogenic conditions, such as gluco-/lipotoxicity (high glucose/palmitate) and inflammation (LPS stimulation) was used to impair $\beta$-cell function, both diabetogenic conditions completely abolished glucose-stimulated insulin secretion (GSIS, Figure 3A) and reduced insulin content (Figure 3B), as shown before in numerous studies $(14,32,33)$. Neither treatment of teduglutide nor a combined teduglutide and GLP-2(3-33) exhibited any impact on GSIS and insulin content in control, high glucose/palmitate or LPS treated human islets (Figures 3A, B). There was also no effect of teduglutide on acute basal and stimulated insulin secretion in human islets (Figure 3C). These data are in line with previous analyses in mouse islets (12) and confirm no effect of GLP-2R activation on insulin secretion in both mouse and human islets.

\section{Intra-Islet GLR-2R Activation Dampened LPS-Induced Islet Inflammation}

GLP-2R activation ameliorates intestinal and hepatic inflammation in various animal models (34-39). Despite no effect on $\beta$-cell function, we reasoned whether GLP-2R activation alters islet 
A

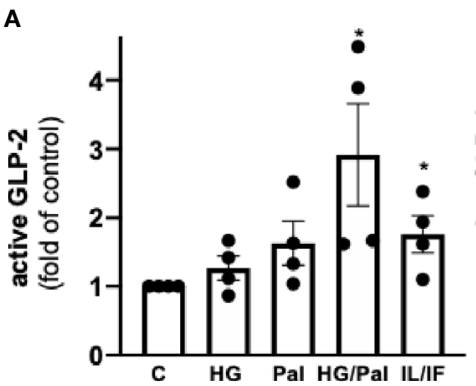

B

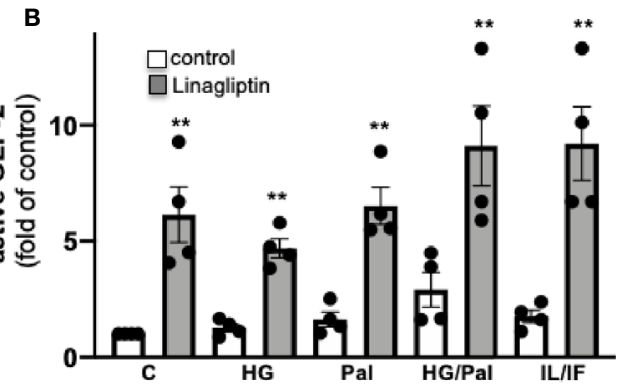

C

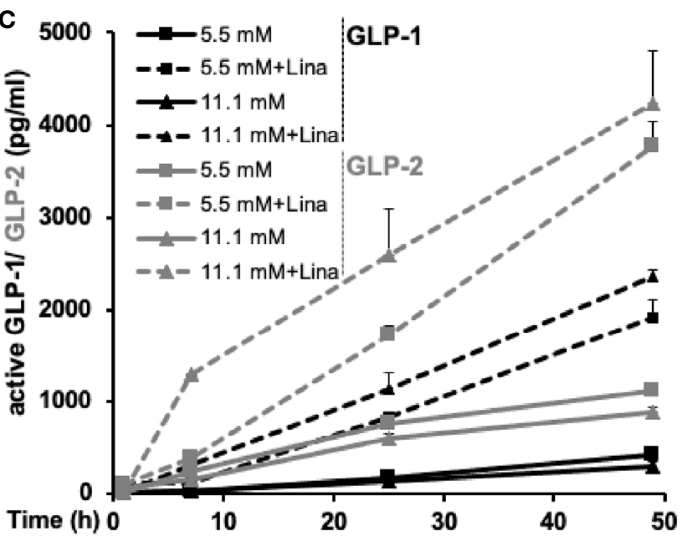

D

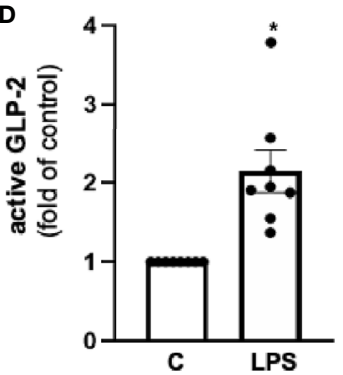

E

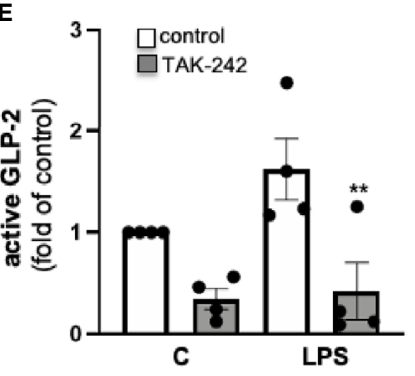

FIGURE 1 | GLP-2 secretion from isolated human islets. Isolated human islets were cultured on ECM-coated dishes (A-C) for $72 \mathrm{~h}$ or during 49 h (C) with 5.5 mM glucose (control; C), $22.2 \mathrm{mM}$ glucose (HG), $0.5 \mathrm{mM}$ palmitate (Pal), a combination of HG/Pal or cytokines $2 \mathrm{ng} / \mathrm{ml} \mathrm{IL-1 \beta /1,000} \mathrm{U/ml} \mathrm{IFN-} \gamma(\mathrm{IL} / \mathrm{IF})$, in the absence (control) or presence of $30 \mathrm{nM}$ linagliptin, or (D, E) for $24 \mathrm{~h}$ with $5.5 \mathrm{mM}$ glucose (control; C) or $20 \mu \mathrm{g} / \mathrm{ml}$ LPS in the absence (control) or presence of $10 \mu \mathrm{M}$ TLR4 inhibitor TAK-242, followed by an ELISA assay of the cell culture supernatants for active GLP-2. Data are normalized to active GLP-2 secretion at untreated control conditions (corresponding to $1.5 \pm 0.3 \mathrm{ng} / 100$ islets into the $2 \mathrm{ml}$ culture medium) and shown as means \pm SEM from $n=4$ (A, B, E) or 8 (D) different human islet isolations. (C) Active GLP-1 and GLP-2 shown as means \pm SEM were analyzed from three different islet isolation; data of active GLP-1 are reproduced and thus are transformative from our earlier study (6), where secreted proteins were analyzed during a 49-hour culture of 60 human islets. ${ }^{*} \mathrm{p}<0.05$ diabetogenic conditions vs. control, ${ }^{* *} \mathrm{p}<0.05$ linagliptin or TAK-242 vs. vehicle control; by paired two-tailed t-test.

inflammation. Using our established LPS stimulation protocol in cultured human islets (14), we observed a significant LPS induced stimulation of $I L 1 B, I L 10$ mRNA as well as a trend towards increased IL6, IL8 and TNF mRNA. LPS-stimulated ILIB and IL10 expression was attenuated by teduglutide and reversed by the combined exposure of the islets to teduglutide and GLP-2(3-33), indicating an GLP-2R dependent effect (Figure 4). In contrast to $I L 1 B$ and IL10 expression, GLP-2R activation had no effect on the mRNA expression levels of IL8, TNF and IL6 (Figure 4).

The difference between these two distinct GLP-2R effects is that TLR4 activated IL1B and IL10 expression in human islets comes by a majority from islet-residing macrophages, while IL8, TNF and IL6 are produced by islet endocrine cells, independent of the presence of macrophages $(22,40)$. Nevertheless, neither human peripheral blood mononuclear cells (PBMCs) nor any types of human monocytes or macrophages express GLP2R (https://www.proteinatlas.org/ENSG00000065325-GLP2R), which we confirmed by qRT-PCR (data not shown). Therefore, we could exclude a direct anti-inflammatory effect of teduglutide, neither on macrophages (no GLP2R expression) nor on endocrine cells (no anti-inflammatory effect) in human islets upon TLR4 activation. 

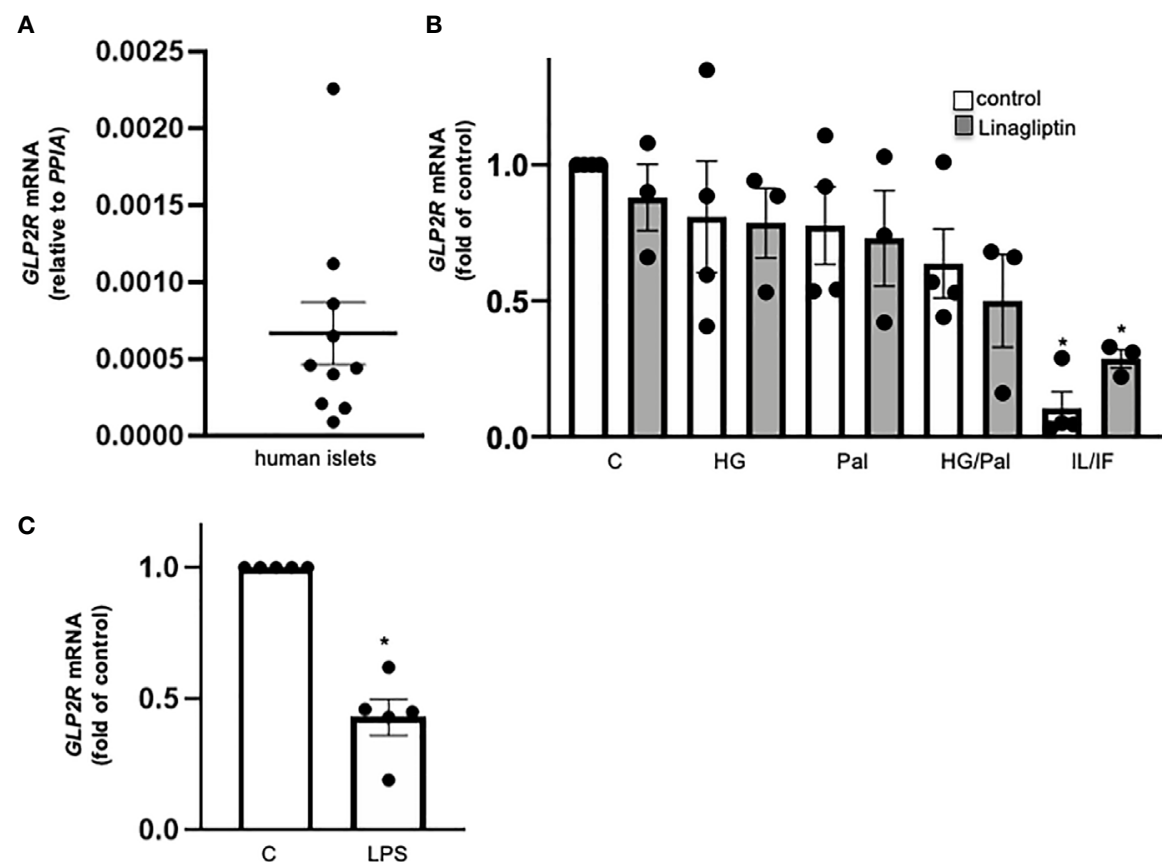

FIGURE 2 | GLP-2R expression in isolated human islets. Isolated human islets were cultured on ECM-coated dishes for 24h (A, C) or 72h (B) under control medium (A) or with $22.2 \mathrm{mM}$ glucose (HG), $0.5 \mathrm{mM}$ palmitate (Pal), or combined HG/Pal or $2 \mathrm{ng} / \mathrm{ml} \mathrm{IL}-1 \beta$ plus 1,000 U/ml IFN- $\gamma$ (IL/IF), in the absence (control) or presence of $30 \mathrm{nM}$ linagliptin (B) or with $20 \mu \mathrm{g} / \mathrm{ml}$ LPS (C). Total mRNA was isolated and GLP2R mRNA analyzed by realtime RT-PCR. Data are shown as means \pm SEM from $n=10$ (A), 4 (B) or 5 (C) different human islet isolations. * $p<0.05$ diabetogenic conditions vs. control by (B) 1-way ANOVA with Dunnet's post-test or (C) paired two-tailed t-test.

\section{Conditioned Medium From Teduglutide- Treated Islets Attenuated M1 Polarization of Human Macrophages}

Consequently, we speculated that the modulatory effect of LPSinduced islet inflammation may come from a crosstalk between GLP-2 responsive islet cells and islet resident macrophages. To test this, we designed a co-culture experiment using conditioned medium from teduglutide and teduglutide/GLP-2(3-33) treated human islets, similarly as described before $(14,22)$. Medium conditioned by cultured untreated human islets $\left(M_{\text {islets }}\right.$ vehicle), islets treated with teduglutide alone $\left(\mathrm{M}_{\text {islets }}\right.$ Teduglutide $)$ or combined with GLP-2(3-33) ( $\mathrm{M}_{\text {islets }}$ Teduglutide/GLP-2(3-33)) were applied to human monocytes derived macrophages (MDMs) during M1-like polarization stimulated by a combination of LPS and IFN- $\gamma$. Gene expression analysis of M1-like macrophages confirmed LPS+IFN- $\gamma$ induced cytokines and chemokines (Figure 5A). IL6, IL8 and IL10 expression was significantly reduced in M1-like macrophages co-cultured with medium from teduglutide treated islets (Figure $\mathbf{5 A}$ ), whereas this phenomenon was abolished by the co-culture medium from human islets treated with the combination of both teduglutide and GLP-2(3-33).

In addition to commonly used cytokines and chemokines as macrophage activation markers, the intracellular metabolite itaconate and succinate are emerging markers recently implicated in proinflammatory macrophage polarization (41-43). To further validate the effect of conditioned medium during M1-like macrophage polarization, we measured the intracellular metabolites of these M1like MDMs by GC-MS. Both itaconate and succinate were highly increased by LPS+IFN- $\gamma$ on M1-like macrophages, compared to vehicle treatment. Co-culture of conditioned medium from human islets treated with teduglutide but not with the combination of teduglutide with GLP-2(3-33) decreased the accumulation of both itaconate and succinate in M1-like MDMs (Figure 5B), suggesting a broad effect of GLP-2R activation to dampen proinflammatory polarization of macrophages. These results support a cell contactindependent paracrine crosstalk between GLP-2 responsive cells and islet macrophages, which contribute to the amelioration of islet inflammation.

\section{Discussion}

In the year 2021, when we celebrate the 100s anniversary of the discovery of insulin, it is just natural that the breakthrough of another family of secreted peptides of common origin from the proglucagon gene: GLP-1, GLP-2 and glucose-dependent insulinotropic polypeptide (GIP) with major implications on the therapy of diabetes was recognized and awarded (44). While the beneficial role of GLP-1 on pancreatic $\beta$-cell survival and function has been extensively studied and well understood, knowledge of GLP-2 in islets is scarce. As $\alpha$-cells secrete GLP1 (2-5) and GLP-1 and GLP-2 are theoretically co-produced through $\mathrm{PC} 1 / 3$-dependent post-translational proglucagon processing, it is assumable that GLP-2 may also be locally 
A

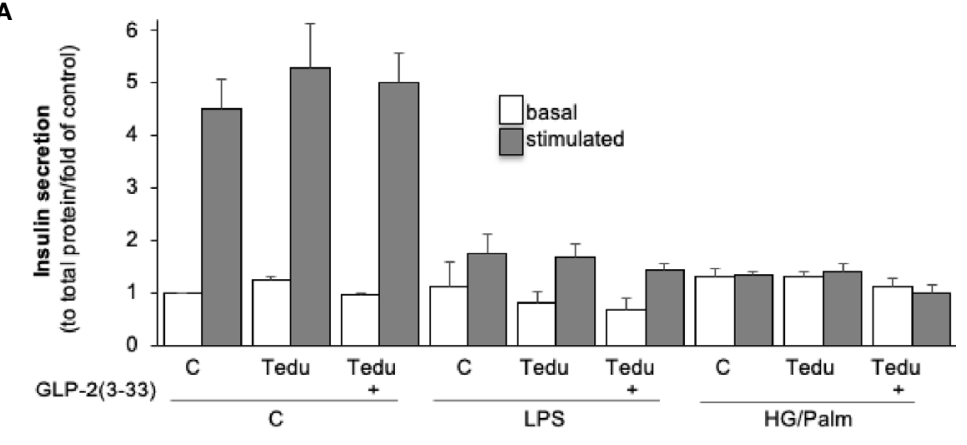

B

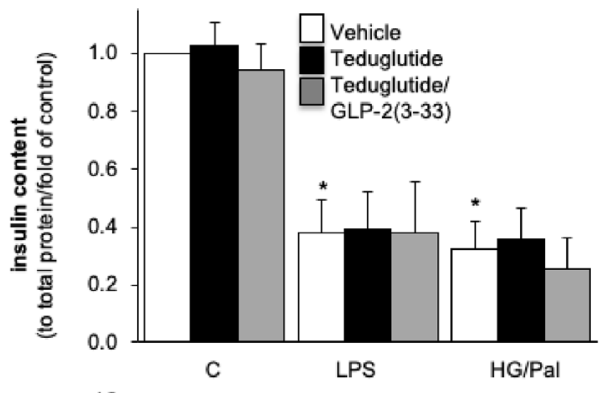

C

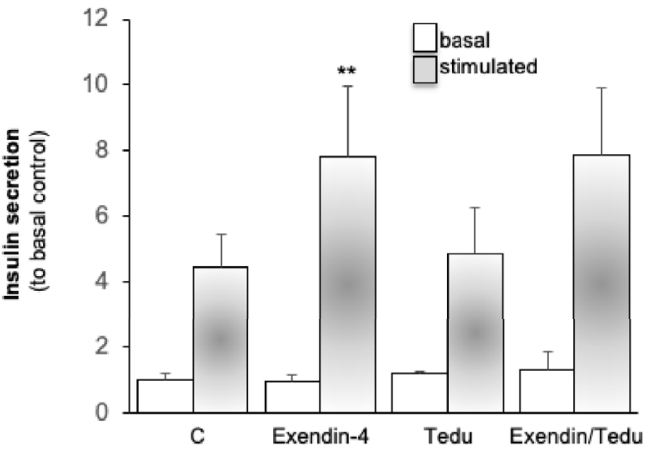

FIGURE 3 | Intra-islet GLR-2R activation with no impact on $\beta$-cell function. Isolated human islets were cultured on ECM-coated dishes and pretreated with $10 \mathrm{nM}$ teduglutide or plus $5 \mathrm{nM}$ GLP-2(3-33) for 2 hours, then LPS or a combined HG/Pal was added into the culture medium and maintained for $72 \mathrm{~h}$. Afterwards, cultured islets were analyzed for (A) glucose-stimulated insulin secretion ( $2.8 \mathrm{mM}$ glucose (basal) for 1 hour, followed by $16.7 \mathrm{mM}$ glucose (stimulated) for 1 hour, and

(B) intracellular insulin content and presented as secreted insulin to total protein content and normalized to the basal control condition (A, B). Acute effect of teduglutide during glucose stimulation; human islets were incubated after the $72 \mathrm{~h}$ culture at control with $2.8 \mathrm{mM}$ glucose (basal) for 1 hour, followed by $16.7 \mathrm{mM}$ glucose (stimulated) for 1 hour with the addition of exendin-4, teduglutide or both (C). Data are presented as means \pm SEM from 3 (A, B) or one (C) different human islet isolations. ${ }^{*} p<0.05 \mathrm{LPS} /$ glucose vs. vehicle control, ${ }^{* *} \mathrm{p}<0.05$ exendin- 4 vs. respective control, both under glucose stimulated conditions by paired two-tailed t-test.

produced in pancreatic islets. In line with this speculation, an ELISA assay specific for detecting active GLP-2 exhibited GLP-2 secretion from cultured human islets which was enhanced by pro-inflammatory diabetogenic conditions. $\alpha$-cell production of PC1/3 and GLP-1 as well as total GLP-1 secretion from human islets are enhanced under situations of $\beta$-cell loss glucotoxicity, lipotoxicity and proinflammatory cytokine exposure $(5,6,45)$. The pro-inflammatory cytokine IL- 6 promotes $\alpha$-cell-derived GLP-1 production (2), and LPS induces intra-islet secretion of IL-6 (14). Hence, it is possible that IL-6 may mediate the enhanced GLP-2 secretion in LPS-treated human islets. Increased GLP-2 secretion together with a reduced GLP-2R expression under the pro-inflammatory stimulation by LPS and the cytokines IL-1 $\beta / \mathrm{IFN} \gamma$ observed in this study further assume GLP-2's potential role during islet inflammation.
GLP-2R is a G protein-coupled receptor (GPCR) responsible for the GLP-2 action (31). It is highly specific for GLP-2 and has only weak affinity to structurally related peptides such as glucagon, GLP-1, and GIP (46). Previous RNASeq analyses did not identify GLP2R expression in human islets $(23,24)$, while it was found in rat islets by transcriptomics but not proteomics analysis (47), indicating a very low expression of GLP2R. This is in line with several elegant peptidomics analyses in human islets, e.g (48-50), which could not identify GLP-2R on the protein level. Using specific membrane extraction methods for protein profiling of human islets it was difficult to identify low abundant proteins; and neither GLP-1R nor GLP-2R were found (51). In addition to the nature of its expression, there is further discrepancy regarding GLP2-R's cellular localization $(11,12)$ in human and rodent islets. Because of their cross reactivity, the 


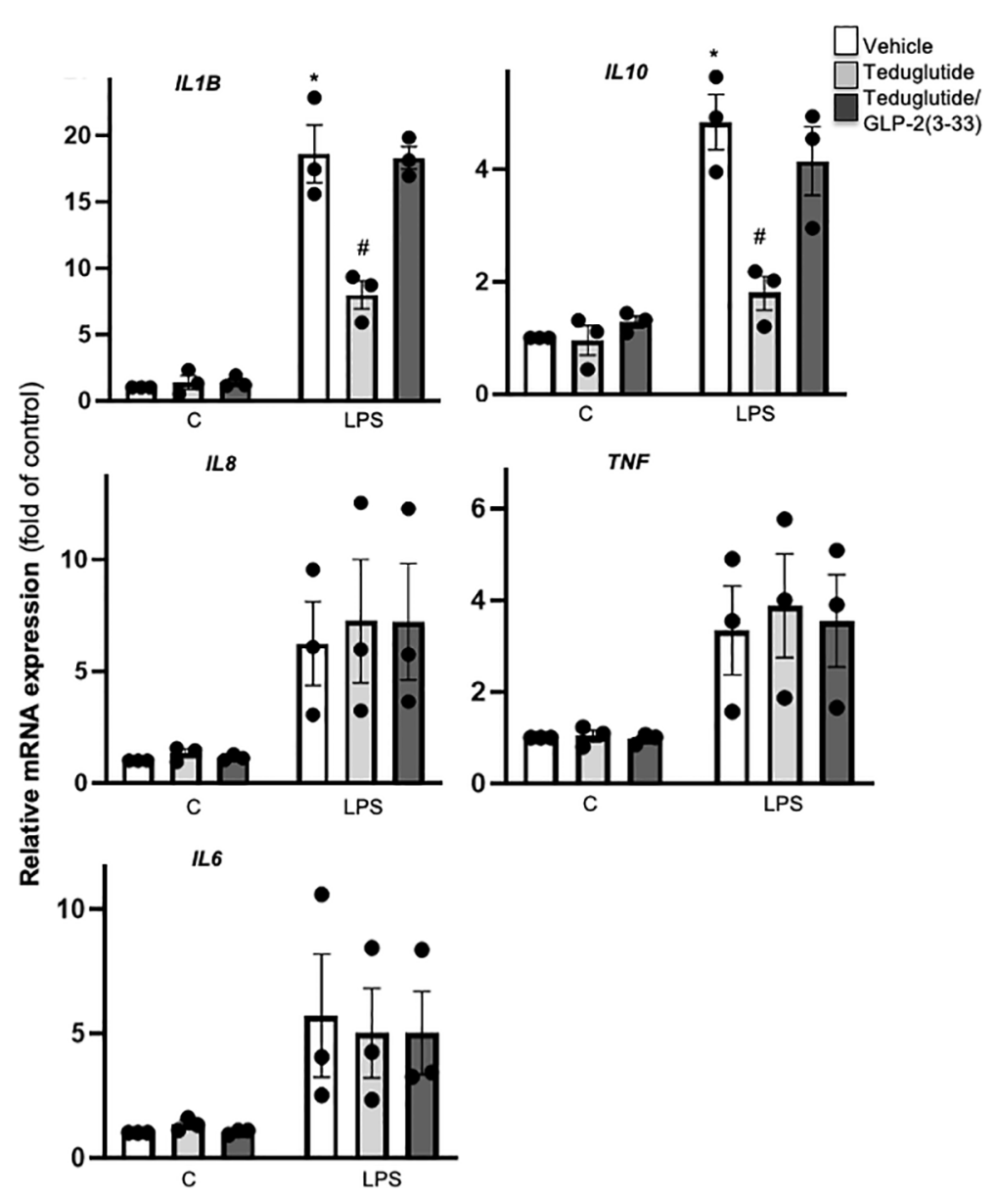

FIGURE 4 | Intra-islet GLR-2R activation dampened LPS-induced islet inflammation. Isolated human islets were cultured on ECM-coated dishes and treated with $10 \mathrm{nM}$ teduglutide or $10 \mathrm{nM}$ teduglutide plus $5 \mathrm{nM}$ GLP-2(3-33) for 2 hours, then LPS was added to the culture medium for 24h. Total RNA was isolated and cytokine and chemokine expression analyzed by realtime RT-PCR. Data are shown as means \pm SEM from $n=3$ different human islet isolations. ${ }^{*} p<0.05$ vs. control, " $\mathrm{p}<0.05$ teduglutide vs. vehicle control by 2-way ANOVA with Sidak's post-test.

specificity issue of various antibodies against glucagon related peptides is well-known; including anti-GLP-2R antibodies, which are insufficient in both sensitivity and specificity (29). Thus, even by using previously evaluated antibodies $(27,28)$, we cannot be sure of the cellular localization in human islets. Two data sets $(25,26)$ identify GLP-2R in human pancreatic stellate cells (PSCs), which is in line with its expression in human and mouse hepatic stellate cells (HSCs) (52). PSCs are multifunctional in the endocrine, where they exist to a small amount of $3 \%$ (24), as well as the exocrine pancreas and are thought to contribute to the inflammatory response as well as to tissue regeneration. Although functionally different, both PSCs and HSCs have almost identical mRNA expression profiles (53) including inflammatory cytokines and chemokines analyzed in the present study, such as IL-1, IL-6, TNF and IL- 8 as well as TLRs. PSC produced IL-8 is well-known to participate in recruiting inflammatory cells and fostering inflammation in the pancreas (53). Importantly and elegantly shown, loss in GLP-2R signals in hepatic stellate cells also contributes to increased hepatic inflammation (52).
Many physiological studies found an anti-inflammatory role of GLP-2 in the gastrointestinal tract. GLP-2 administration exhibits prominent anti-inflammatory effects in intestinal mucosa of various murine models of colitis $(34,35,38,39)$ and in a postoperative ileus mouse model (37). In vitro studies at the cellular level are rare, partly due to the fact that GLP-2R is absent in immune cells. In our current ex vivo study, GLP-2R activation by teduglutide reduced LPS-induced $I L I B$ and $I L 10$ expression in human islets. Both cytokines are dependent on islet-associated macrophages $(22,40)$, whereas macrophages do not express GLP-2R. A plausible speculation would be a crosstalk between GLP-2 responsive intra-islet cells and islet resident macrophages. To support this, primary human macrophages cultured with conditioned medium from teduglutide-treated human islets display dampened M1 polarization, specifically seen by the reduced IL6, IL8 and IL10 expression. Pro-inflammatory macrophage activation is associated with reprogrammed intracellular metabolism, featuring accumulation of itaconate and succinate (41-43). Both metabolites were reduced in the 

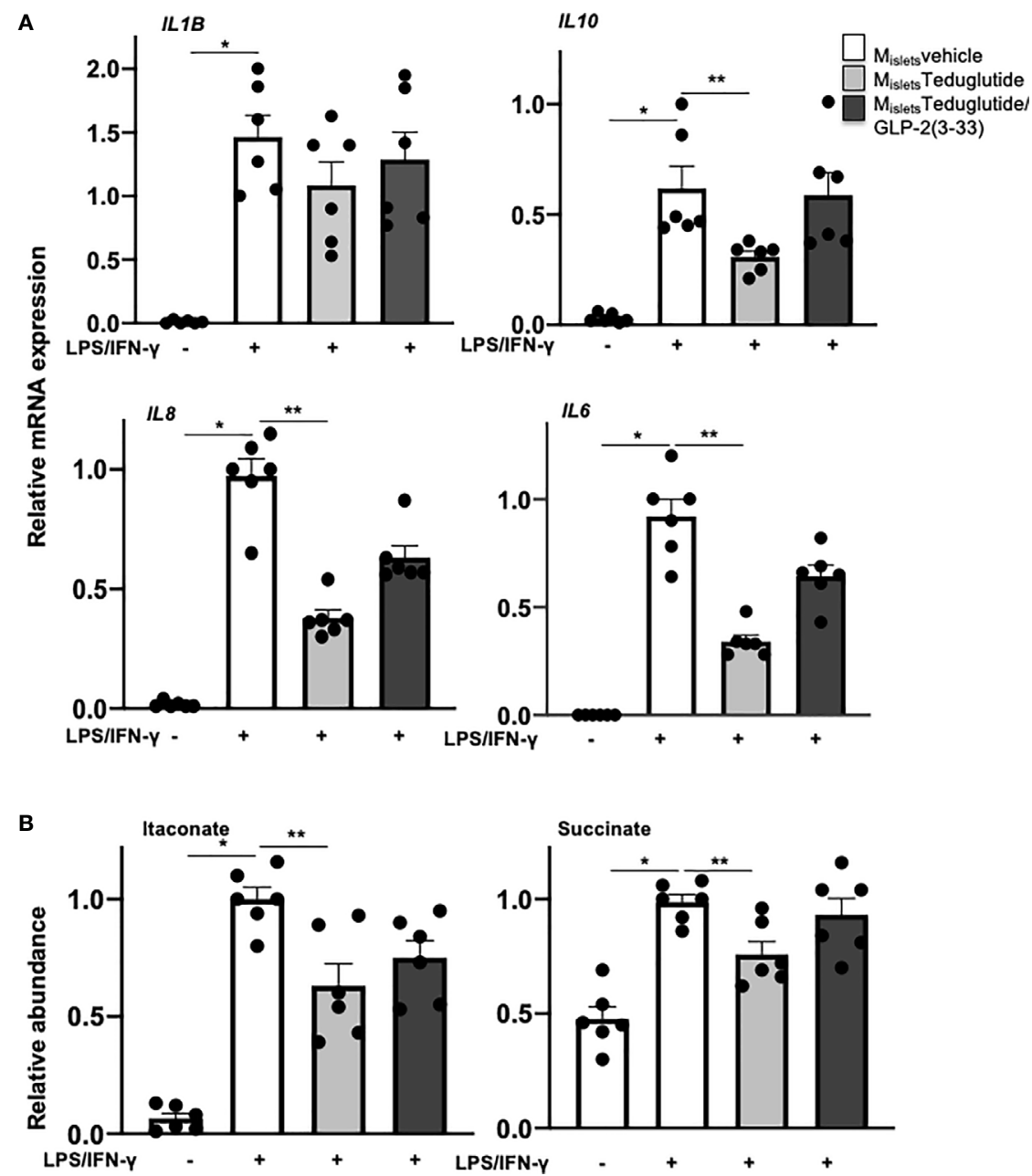

FIGURE 5 | Conditioned medium from teduglutide-treated islets attenuated M1 polarization of human macrophages. Primary human monocyte-derived macrophages (by M-CSF) were cultured in medium pre-conditioned by cultured untreated human islets ( $\mathrm{M}_{\text {islets }}$ vehicle) or islets treated with teduglutide alone ( $\mathrm{M}_{\text {islets }}$ Teduglutide) or combined with GLP-2(3-33) (Mislets Teduglutide/GLP-2(3-33)) for 2h, then LPS/IFN- $\gamma$ was added to the culture and maintained for 8h to induce M1-like polarization, followed by (A) total RNA isolation and cytokine expression analysis by realtime RT-PCR and (B) intracellular metabolite extraction and measurement by GC-MS. Data are presented as means \pm SEM from $n=6$ biological replicates pooled from two independent experiments of two different

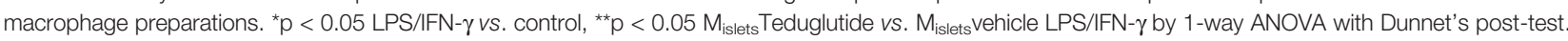

M1 macrophages cultured with the teduglutide-treated islet conditioned medium, implying that a GLP-2 induced intraislet crosstalk broadly affects M1 macrophage polarization, rather than simply influences cytokine expression. In ex vivo experiments in human islets, teduglutide was able to reduce macrophage dependent $I L 1 B$ expression, which did not happen in primary MDMs cultured with conditioned medium, despite repetitive efforts and parallel analyses of IL6,IL8 and IL10, which were indeed reduced by teduglutide-treated islet medium. The different macrophage origin in this experimental setting [islet resident macrophages mainly originate during embryogenesis while primary monocytes are from adult hematogenesis (54, 55)], as well as the islet microenvironment may be accountable for such discrepancy. The pancreatic islet microenvironment is also known to shape a unique phenotype of resident macrophages (56). Although islet conditioned medium contains islet microenvironment-derived soluble factors, temporal effects of intra-islet crosstalk cannot be recapitulated. Nevertheless, GLP-2's anti-inflammatory action in the intestine, which is mediated by a crosstalk in which GLP-2R expressing enteric neurons secrete vasoactive intestinal polypeptides (VIPs) which in turn elicit anti-inflammatory effects on intestinal immune cells (35) would also support an intra-islet crosstalk triggered by GLP-2 action, in which GLP-2R activation is able to reduce macrophage dependent cytokine expression within human islets. Thus, it seems a common way for GLP-2 to exert anti-inflammatory effects through a crosstalk between GLP-2 responsive cells, which do express GLP-2R and immune cells, which do not express GLP-2R. Macrophage derived inflammatory factors are prominently targeted, as shown in our study, where macrophage dependent IL1B and IL10 expressions are reduced by GLP-2R agonism, but not 
endocrine cell dependent IL8, TNF and IL6. Such has been confirmed by direct MDM analysis, where IL6 and IL8 mRNA was also reduced by teduglutide exposed islets.

In terms of glucose homeostasis, current knowledge does not indicate a direct GLP-2 effect, either through acute administration or chronic effects. GLP-2R activation neither affected insulin secretion in isolated human islets in this study, nor had an effect in mouse islets, but increases glucagon secretion in rat pancreata $(11,12)$. In vivo studies also indicate no direct impact of GLP-2R signaling on glucose homeostasis by either acute GLP-2 administration or chronically in GLP-2R-deficient mice $(12,57,58)$. Therefore, in contrast to its co-product GLP-1, GLP-2 is unlikely to directly regulate glucose homeostasis.

Considering GLP-2's anti-inflammatory action, it is conceivable that activation of GLP-2R and its downstream signaling dampen chronic inflammation and hereby protect $\beta$ cells. Therefore, future studies should focus on the effect of GLP2 in a context of a long-term diabetogenic scenario.

In summary, we have revealed intra-islet production of GLP2 and confirmed GLP-2R expression in human islets. Local activation of GLP-2R had no impact on $\beta$-cell function but attenuates islet inflammation by reducing the local activation of pro-inflammatory macrophages. Much further in-depth research is needed to understand GLP-2's action in the pancreas and the physiological role of secreted GLP-2 and its consequent degradation by DPP4.

\section{DATA AVAILABILITY STATEMENT}

The raw data supporting the conclusions of this article will be made available by the authors, without undue reservation.

\section{ETHICS STATEMENT}

Ethical approval for the use of human islets had been granted by the Ethics Committee of the University of Bremen. The study complied with all relevant ethical regulations for work with human cells for research purposes. Written informed consent for participation was not required for this study in accordance with the national legislation and the institutional requirements.

\section{REFERENCES}

1. Campbell JE, Drucker DJ. Pharmacology, Physiology, and Mechanisms of Incretin Hormone Action. Cell Metab (2013) 17:819-37. doi: 10.1016/ j.cmet.2013.04.008

2. Ellingsgaard H, Hauselmann I, Schuler B, Habib AM, Baggio LL, Meier DT, et al. Interleukin-6 Enhances Insulin Secretion by Increasing Glucagon-Like Peptide-1 Secretion From L Cells and Alpha Cells. Nat Med (2011) 17:1481-9. doi: $10.1038 / \mathrm{nm} .2513$

3. Marchetti P, Lupi R, Bugliani M, Kirkpatrick CL, Sebastiani G, Grieco FA, et al. A Local Glucagon-Like Peptide 1 (GLP-1) System in Human Pancreatic Islets. Diabetologia (2012) 55:3262-72. doi: 10.1007/s00125-012-2716-9

4. Moffett RC, Vasu S, Thorens B, Drucker DJ, Flatt PR. Incretin Receptor Null Mice Reveal Key Role of GLP-1 But Not GIP in Pancreatic Beta Cell Adaptation to Pregnancy. PLoS One (2014) 9:e96863. doi: 10.1371/journal.pone.0096863
Organ donors are not identifiable and anonymous, such approved experiments using human islet cells for research is covered by the NIH Exemption 4 (Regulation PHS 398).

\section{AUTHOR CONTRIBUTIONS}

Conceptualization: KM, WH, TK. Methodology and analysis: $\mathrm{KM}$ (Figures 1-4), WH (Figures 1-5), OR (Figures 1-3), AH, FN (Figure 5). Manuscript writing and editing: KM, WH, TK. Resources: KM, TK. Funding acquisition: KM, TK, Supervision: $\mathrm{KM}, \mathrm{WH}, \mathrm{TK}$. All authors contributed to the article and approved the submitted version.

\section{FUNDING}

This work was supported by JDRF and the German Research Foundation (DFG). Human pancreatic islets were kindly provided by the NIDDK-funded Integrated Islet Distribution Program (IIDP) at City of Hope, NIH Grant \# 2UC4DK098085, the JDRF-funded IIDP Islet Award Initiative and through the ECIT Islet for Basic Research program supported by JDRF (JDRF award 31-2008-413).

\section{ACKNOWLEDGMENTS}

We thank J. Kerr-Conte and Francois Pattou (European Genomic Institute for Diabetes, Lille) for high quality human islet isolations, Katja Thode (Boehringer Ingelheim) and Katrischa Hennekens for excellent technical assistance, Petra Schilling for pancreas sectioning and Amin Ardestani (all University of Bremen) for fruitful discussion and help with the analyses.

\section{SUPPLEMENTARY MATERIAL}

The Supplementary Material for this article can be found online at: https://www.frontiersin.org/articles/10.3389/fendo.2021. 697120/full\#supplementary-material

5. Whalley NM, Pritchard LE, Smith DM, White A. Processing of Proglucagon to GLP-1 in Pancreatic Alpha-Cells: Is This a Paracrine Mechanism Enabling GLP-1 to Act on Beta-Cells? J Endocrinol (2011) 211:99-106. doi: 10.1530/JOE-11-0094

6. Shah P, Ardestani A, Dharmadhikari G, Laue S, Schumann DM, Kerr-Conte J, et al. The DPP-4 Inhibitor Linagliptin Restores Beta-Cell Function and Survival in Human Isolated Islets Through GLP-1 Stabilization. J Clin Endocr Metab (2013) 98:E1163-72. doi: 10.1210/jc.2013-1029

7. Mulvihill EE, Drucker DJ. Pharmacology, Physiology, and Mechanisms of Action of Dipeptidyl Peptidase-4 Inhibitors. Endocr Rev (2014) 35:992-1019. doi: 10.1210/er.2014-1035

8. Muller TD, Finan B, Bloom SR, D’Alessio D, Drucker DJ, Flatt PR, et al. Glucagon-Like Peptide 1 (GLP-1). Mol Metab (2019) 30:72-130. doi: 10.1016/j.molmet.2019.09.010

9. Drucker DJ. The Discovery of GLP-2 and Development of Teduglutide for Short Bowel Syndrome. ACS Pharmacol Transl Sci (2019) 2:134-42. doi: $10.1021 /$ acsptsci.9b00016 
10. Janssen P, Rotondo A, Mule F, Tack J. Review Article: A Comparison of Glucagon-Like Peptides 1 and 2. Aliment Pharmacol Ther (2013) 37:18-36. doi: 10.1111/apt.12092

11. de Heer J, Pedersen J, Orskov C, Holst JJ. The Alpha Cell Expresses GlucagonLike Peptide-2 Receptors and Glucagon-Like Peptide-2 Stimulates Glucagon Secretion From the Rat Pancreas. Diabetologia (2007) 50:2135-42. doi: 10.1007/s00125-007-0761-6

12. Khan D, Vasu S, Moffett RC, Irwin N, Flatt PR. Differential Expression of Glucagon-Like Peptide-2 (GLP-2) is Involved in Pancreatic Islet Cell Adaptations to Stress and Beta-Cell Survival. Peptides (2017) 95:68-75. doi: 10.1016/j.peptides.2017.07.011

13. Yusta B, Matthews D, Koehler JA, Pujadas G, Kaur KD, Drucker DJ. Localization of Glucagon-Like Peptide-2 Receptor Expression in the Mouse. Endocrinology (2019) 160:1950-63. doi: 10.1210/en.2019-00398

14. He W, Rebello O, Savino R, Terracciano R, Schuster-Klein C, Guardiola B, et al. TLR4 Triggered Complex Inflammation in Human Pancreatic Islets. Biochim Biophys Acta Mol Basis Dis (2019) 1865:86-97. doi: 10.1016/ j.bbadis.2018.09.030

15. Takashima K, Matsunaga N, Yoshimatsu M, Hazeki K, Kaisho T, Uekata M, et al. Analysis of Binding Site for the Novel Small-Molecule TLR4 Signal Transduction Inhibitor TAK-242 and its Therapeutic Effect on Mouse Sepsis Model. Br J Pharmacol (2009) 157:1250-62. doi: 10.1111/j.14765381.2009.00297.x

16. Matsunaga N, Tsuchimori N, Matsumoto T, Ii M. TAK-242 (Resatorvid), a Small-Molecule Inhibitor of Toll-Like Receptor (TLR) 4 Signaling, Binds Selectively to TLR4 and Interferes With Interactions Between TLR4 and its Adaptor Molecules. Mol Pharmacol (2011) 79:34-41. doi: 10.1124/ mol.110.068064

17. Maedler K, Spinas GA, Dyntar D, Moritz W, Kaiser N, Donath MY. Distinct Effects of Saturated and Monounsaturated Fatty Acids on Beta-Cell Turnover and Function. Diabetes (2001) 50:69-76. doi: 10.2337/diabetes.50.1.69

18. Sharkovska Y, Reichetzeder C, Alter M, Tsuprykov O, Bachmann S, Secher T, et al. Blood Pressure and Glucose Independent Renoprotective Effects of Dipeptidyl Peptidase-4 Inhibition in a Mouse Model of Type-2 Diabetic Nephropathy. J Hypertens (2014) 32:2211-23. doi: 10.1097/HJH. 0000000000000328

19. Hart NJ, Powers AC. Use of Human Islets to Understand Islet Biology and Diabetes: Progress, Challenges and Suggestions. Diabetologia (2019) 62:21222. doi: 10.1007/s00125-018-4772-2

20. Meiser J, Kramer L, Sapcariu SC, Battello N, Ghelfi J, D’Herouel AF, et al. ProInflammatory Macrophages Sustain Pyruvate Oxidation Through Pyruvate Dehydrogenase for the Synthesis of Itaconate and to Enable Cytokine Expression. J Biol Chem (2016) 291:3932-46. doi: 10.1074/jbc.M115.676817

21. Hiller K, Hangebrauk J, Jager C, Spura J, Schreiber K, Schomburg D. MetaboliteDetector: Comprehensive Analysis Tool for Targeted and Nontargeted GC/MS Based Metabolome Analysis. Anal Chem (2009) 81:3429-39. doi: 10.1021/ac802689c

22. He W, Yuan T, Maedler K. Macrophage-Associated Pro-Inflammatory State in Human Islets From Obese Individuals. Nutr Diabetes (2019) 9:36. doi: 10.1038/s41387-019-0103-Z

23. Blodgett DM, Nowosielska A, Afik S, Pechhold S, Cura AJ, Kennedy NJ, et al. Novel Observations From Next-Generation RNA Sequencing of Highly Purified Human Adult and Fetal Islet Cell Subsets. Diabetes (2015) 64:3172-81. doi: 10.2337/db15-0039

24. Fasolino M, Schwartz GW, Golson ML, Wang YJ, Morgan A, Liu C, et al. Multiomics Single-Cell Analysis of Human Pancreatic Islets Reveals Novel Cellularstates in Health and Type 1 Diabetes. bioRxiv preprint (2021). doi: 10.1101/2021.01.28.428598

25. Fang Z, Weng C, Li H, Tao R, Mai W, Liu X, et al. Single-Cell Heterogeneity Analysis and CRISPR Screen Identify Key Beta-Cell-Specific Disease Genes. Cell Rep (2019) 26:3132-44.e7. doi: 10.1016/j.celrep.2019.02.043

26. Weng C, Xi J, Li H, Cui J, Gu A, Lai S, et al. Single-Cell Lineage Analysis Reveals Extensive Multimodal Transcriptional Control During Directed Beta-Cell Differentiation. Nat Metab (2020) 2:1443-58. doi: 10.1038/s42255-020-00314-2

27. Guan X, Karpen HE, Stephens J, Bukowski JT, Niu S, Zhang G, et al. GLP-2 Receptor Localizes to Enteric Neurons and Endocrine Cells Expressing Vasoactive Peptides and Mediates Increased Blood Flow. Gastroenterology (2006) 130:150-64. doi: 10.1053/j.gastro.2005.11.005
28. Baldassano S, Liu S, Qu MH, Mule F, Wood JD. Glucagon-Like Peptide-2 Modulates Neurally Evoked Mucosal Chloride Secretion in Guinea Pig Small Intestine In Vitro. Am J Physiol Gastrointest Liver Physiol (2009) 297:G800-5. doi: 10.1152/ajpgi.00170.2009

29. Drucker DJ, Yusta B. Physiology and Pharmacology of the Enteroendocrine Hormone Glucagon-Like Peptide-2. Annu Rev Physiol (2014) 76:561-83. doi: 10.1146/annurev-physiol-021113-170317

30. Thulesen J, Knudsen LB, Hartmann B, Hastrup S, Kissow H, Jeppesen PB, et al. The Truncated Metabolite GLP-2 (3-33) Interacts With the GLP-2 Receptor as a Partial Agonist. Regul Pept (2002) 103:9-15. doi: 10.1016/S01670115(01)00316-0

31. Munroe DG, Gupta AK, Kooshesh F, Vyas TB, Rizkalla G, Wang H, et al. Prototypic G Protein-Coupled Receptor for the Intestinotrophic Factor Glucagon-Like Peptide 2. Proc Natl Acad Sci U S A (1999) 96:1569-73. doi: 10.1073/pnas.96.4.1569

32. Ardestani A, Paroni F, Azizi Z, Kaur S, Khobragade V, Yuan T, et al. MST1 is a Key Regulator of Beta Cell Apoptosis and Dysfunction in Diabetes. Nat Med (2014) 20:385-97. doi: 10.1038/nm.3482

33. Amyot J, Semache M, Ferdaoussi M, Fontes G, Poitout V. Lipopolysaccharides Impair Insulin Gene Expression in Isolated Islets of Langerhans via Toll-Like Receptor-4 and NF-kappaB Signalling. PLoS One (2012) 7:e36200. doi: 10.1371/journal.pone.0036200

34. Ivory CP, Wallace LE, McCafferty DM, Sigalet DL. Interleukin-10Independent Anti-Inflammatory Actions of Glucagon-Like Peptide 2. Am J Physiol Gastrointest Liver Physiol (2008) 295:G1202-10. doi: 10.1152/ ajpgi.90494.2008

35. Sigalet DL, Wallace LE, Holst JJ, Martin GR, Kaji T, Tanaka H, et al. Enteric Neural Pathways Mediate the Anti-Inflammatory Actions of Glucagon-Like Peptide 2. Am J Physiol Gastrointest Liver Physiol (2007) 293:G211-21. doi: 10.1152/ajpgi.00530.2006

36. Cani PD, Possemiers S, Van de Wiele T, Guiot Y, Everard A, Rottier O, et al. Changes in Gut Microbiota Control Inflammation in Obese Mice Through a Mechanism Involving GLP-2-Driven Improvement of Gut Permeability. Gut (2009) 58:1091-103. doi: 10.1136/gut.2008.165886

37. Moore BA, Peffer N, Pirone A, Bassiri A, Sague S, Palmer JM, et al. GLP-2 Receptor Agonism Ameliorates Inflammation and Gastrointestinal Stasis in Murine Postoperative Ileus. J Pharmacol Exp Ther (2010) 333:574-83. doi: 10.1124/jpet.109.161497

38. Qi KK, Wu J, Deng B, Li YM, Xu ZW. PEGylated Porcine Glucagon-Like Peptide-2 Improved the Intestinal Digestive Function and Prevented Inflammation of Weaning Piglets Challenged With LPS. Animal (2015) 9:1481-9. doi: 10.1017/S1751731115000749

39. Nakame K, Kaji T, Mukai M, Shinyama S, Matsufuji H. The Protective and Anti-Inflammatory Effects of Glucagon-Like Peptide-2 in an Experimental Rat Model of Necrotizing Enterocolitis. Peptides (2016) 75:1-7. doi: 10.1016/ j.peptides.2015.07.025

40. Nackiewicz D, Dan M, He W, Kim R, Salmi A, Rutti S, et al. TLR2/6 and TLR4-Activated Macrophages Contribute to Islet Inflammation and Impair Beta Cell Insulin Gene Expression via IL-1 and IL-6. Diabetologia (2014) 57:1645-54. doi: 10.1007/s00125-014-3249-1

41. Murphy MP, O’Neill LAJ. Krebs Cycle Reimagined: The Emerging Roles of Succinate and Itaconate as Signal Transducers. Cell (2018) 174:780-4. doi: 10.1016/j.cell.2018.07.030

42. Ryan DG, O’Neill LAJ. Krebs Cycle Reborn in Macrophage Immunometabolism. Annu Rev Immunol (2020) 38:289-313. doi: 10.1146/ annurev-immunol-081619-104850

43. He W, Heinz A, Jahn D, Hiller K. Complexity of Macrophage Metabolism in Infection. Curr Opin Biotechnol (2021) 68:231-9. doi: 10.1016/j.copbio. 2021.01.020

44. O'Rahilly S. The Islet's Bridesmaid Becomes the Bride: Proglucagonderived Peptides Deliver Transformative Therapies. Cell (2021) 184(8):1945-8. doi: 10.1016/j.cell.2021.03.019

45. Huang C, Yuan L, Cao S. Endogenous GLP-1 as a Key Self-Defense Molecule Against Lipotoxicity in Pancreatic Islets. Int J Mol Med (2015) 36:173-85. doi: 10.3892/ijmm.2015.2207

46. DaCambra MP, Yusta B, Sumner-Smith M, Crivici A, Drucker DJ, Brubaker PL. Structural Determinants for Activity of Glucagon-Like Peptide-2. Biochemistry-Us (2000) 39:8888-94. doi: 10.1021/bi000497p 
47. Hou J, Li Z, Zhong W, Hao Q, Lei L, Wang L, et al. Temporal Transcriptomic and Proteomic Landscapes of Deteriorating Pancreatic Islets in Type 2 Diabetic Rats. Diabetes (2017) 66:2188-200. doi: 10.2337/db16-1305

48. Nakayasu ES, Syed F, Tersey SA, Gritsenko MA, Mitchell HD, Chan CY, et al. Comprehensive Proteomics Analysis of Stressed Human Islets Identifies GDF15 as a Target for Type 1 Diabetes Intervention. Cell Metab (2020) 31:363-74.e6. doi: 10.1016/j.cmet.2019.12.005

49. Zhang L, Lanzoni G, Battarra M, Inverardi L, Zhang Q. Proteomic Profiling of Human Islets Collected From Frozen Pancreata Using Laser Capture Microdissection. J Proteomics (2017) 150:149-59. doi: 10.1016/j.jprot. 2016.09.002

50. Metz TO, Jacobs JM, Gritsenko MA, Fontes G, Qian WJ, Camp DG2nd, et al. Characterization of the Human Pancreatic Islet Proteome by Two-Dimensional LC/MS/MS. J Proteome Res (2006) 5:3345-54. doi: 10.1021/pr060322n

51. Hansson SF, Henriksson A, Johansson L, Korsgren O, Eriksson JW, Tornqvist H, et al. Membrane Protein Profiling of Human Islets of Langerhans Using Several Extraction Methods. Clin Proteom (2010) 6:195-207. doi: 10.1007/s12014-0109060-1

52. Fuchs S, Yusta B, Baggio LL, Varin EM, Matthews D, Drucker DJ. Loss of Glp2r Signaling Activates Hepatic Stellate Cells and Exacerbates Diet-Induced Steatohepatitis in Mice. JCI Insight (2020) 5(8):e136907. doi: 10.1172/ jci.insight. 136907

53. Masamune A, Watanabe T, Kikuta K, Shimosegawa T. Roles of Pancreatic Stellate Cells in Pancreatic Inflammation and Fibrosis. Clin Gastroenterol Hepatol (2009) 7:S48-54. doi: 10.1016/j.cgh.2009.07.038

54. Perdiguero EG, Geissmann F. The Development and Maintenance of Resident Macrophages. Nat Immunol (2016) 17:2-8. doi: 10.1038/ni.3341
55. Okabe Y, Medzhitov R. Tissue Biology Perspective on Macrophages. Nat Immunol (2016) 17:9-17. doi: 10.1038/ni.3320

56. Unanue ER. Macrophages in Endocrine Glands, With Emphasis on Pancreatic Islets. Microbiol Spectr (2016) 4(6):10.1128. doi: 10.1128/microbiolspec. MCHD-0048-2016

57. Meier JJ, Nauck MA, Pott A, Heinze K, Goetze O, Bulut K, et al. GlucagonLike Peptide 2 Stimulates Glucagon Secretion, Enhances Lipid Absorption, and Inhibits Gastric Acid Secretion in Humans. Gastroenterology (2006) 130:44-54. doi: 10.1053/j.gastro.2005.10.004

58. Bahrami J, Longuet C, Baggio LL, Li K, Drucker DJ. Glucagon-Like Peptide-2 Receptor Modulates Islet Adaptation to Metabolic Stress in the Ob/Ob Mouse. Gastroenterology (2010) 139:857-68. doi: 10.1053/j.gastro.2010.05.006

Conflict of Interest: TK is an employee of Boehringer Ingelheim Pharma. Linagliptin is a Boehringer Ingelheim Pharma product.

The remaining authors declare that the research was conducted in the absence of any commercial or financial relationships that could be construed as a potential conflict of interest.

Copyright $\odot 2021$ He, Rebello, Henne, Nikolka, Klein and Maedler. This is an openaccess article distributed under the terms of the Creative Commons Attribution License (CC BY). The use, distribution or reproduction in other forums is permitted, provided the original author(s) and the copyright owner(s) are credited and that the original publication in this journal is cited, in accordance with accepted academic practice. No use, distribution or reproduction is permitted which does not comply with these terms. 